\title{
Invitacions per a la formació de mestres
}

\author{
Francisco Esteban Bara* \\ Ferran Sánchez Margalef ${ }^{* *}$
}

Resum

Necessitem bons professors, els millors possibles. Professionals de l'educació que acumulin molts coneixements i els sàpiguen explicar, que estiguin a l'última en noves tecnologies i en noves corrents psicopedagògiques, i també requerim professors que compleixin amb la deontologia de la professió docent. Ara bé, són només així els bons professors que necessitem? Una cosa ens diu que no, sent aquesta cosa la pròpia experiència. Hem tingut professors que no han passat per les nostres vides, sinó que s'hi han quedat, en elles. Ells van fer coses impossibles d'esborrar de les nostres ments i ànimes, ells van tenir gestos típicament humans, senzills i bonics. Aquests professors ens demostren que l'educació pot arribar a ser una meravellosa aventura humanitzadora, un autèntic esdeveniment de transformació humana. Aquest treball presenta algunes invitacions per a la formació d'aquest tipus de mestres.

\section{Paraules clau}

Formació de mestres, Ètica, Formació del caràcter, Educació Superior.

Recepció original: 08 de març de 2019

Acceptació: 04 de setembre de 2019

Publicació: 20 de gener de 2020

\section{Introducció}

Imaginem que algú se situa en un concorregut carrer d'alguna de les nostres ciutats, i planteja als vianants la següent pregunta: quins professors vol vostè per als seus fills, les nostres escoles, la nostra comunitat, per a aquest món en què vivim? Podem afirmar, i desitjaríem no equivocar-nos, que el càndid personatge rebria una resposta majoritària que es podria resumir de la següent manera: què vol que li digui, vull bons professors, els millors possibles! I també podem vaticinar amb certa seguretat, que després d'aquesta escarida i contundent contestació trobaríem diverses interpretacions. Una d'elles: hi haurà gent per a la qual els bons professors són aquells que tenen molts coneixements, que saben explicar tot el que saben, que estan a l'última en noves tecnologies i en noves corrents pedagògiques, que moti-

$\left(^{*}\right.$ Doctor en Pedagogia i doctor en Filosofia, professor del Departament de Teoria i Història de l'Educació de la Universitat de Barcelona (UB) i membre del grup consolidat de Recerca en Educació Moral (GREM). Les seves investigacions estan centrades en la formació del caràcter dels mestres i la filosofia de la formació universitària, àmbits sobre els quals té diverses publicacions internacionals. Adreça electrònica: franciscoesteban@ub.edu

${ }^{(* *}$ Professor associat del Departament de Teoria i Història de l'Educació de la Universitat de Barcelona, on imparteix docència sobre qüestions deontològiques i axiològiques de l'educació. Col·laborador del GREM (Grup de Recerca en Educació Moral) i del GREPPS (Grup de Recerca en Pensament Pedagògic i Social), ambdós de la Universitat de Barcelona. La seva línia de recerca atén la trajectòria pedagògica humanista i, molt especialment, el repte del transhumanisme. Adreça electrònica: ferran.sanchez@ub.edu 
ven els seus alumnes, que s'entenen amb les famílies, que detecten i solucionin dificultats d'aprenentatge, problemes d'actitud i comportament, etc. En definitiva, autèntics professionals, individus qualificats i preparats per lluitar amb qualsevol circumstància educativa que se'ls posin per davant.

Hi ha una altra accepció possible i no menys important que l'anterior. Hi haurà gent que amb això d'excel-lents professors, els més excel-lents que es puguin imaginar, s'estigui referint a persones que encaren la tasca educativa amb una mínima i consistent ètica professional. Cada vegada més, i sens dubte és bo que així sigui, es pensa que els bons professors són aquells que compleixen amb la deontologia de la professió docent, amb el conjunt de compromisos i deures que un professor ha d'assumir, per exemple, en relació amb els alumnes, les famílies, els companys de treball, la mateixa professió o la societat en el seu conjunt. En aquest marc ètic es reuneixen qüestions tan importants i necessàries com són l'exercici de la responsabilitat en totes les actuacions que un professor realitza dia rere dia, la defensa de la veracitat i l'objectivitat a l'hora d'explicar les coses, la demostració de respecte davant la diversitat cultural i social, el compromís amb la seva formació permanent, etc. La llista de compromisos i deures ètics del professor d'avui pot arribar a ser, com és lògic pensar, considerable.

Les dues apreciacions anteriors són clares i manifestes. A ningú amb un mínim de sentit comú se li acudiria defensar el contrari. A més, sembla que són les dues cares d'una mateixa moneda, es necessiten una a l'altra per poder parlar d'aquests bons professors que volem i necessitem. Un professor entès en les seves tasques com el que més, però sense ètica professional, és un perill errant; i un professor que compleix amb la deontologia professional al peu de la lletra, però que emmalalteix de les competències que se li suposen a un expert en educació sol caure en la imprudència i la temeritat. És més, hauríem de preguntar-nos si tant l'un com l'altre, que coixegen d'algun dels aspectes essencials assenyalats, són realment professors per molt que així se'ls digui. Ara bé, ser competent en una determinada professió i comportar-se segons marquen els seus particulars compromisos i deures ètics són característiques necessàries de qualsevol bon professional en el qual puguem pensar. Això incumbeix al bon metge, arquitecte, advocat, lampista o comerciant. Però aquí no estem parlant d'altres professionals, sinó de mestres, i cal preguntar-se: això és tot i parem de comptar?, són només així els bons professors que volem?, és suficient que disposin de coneixements, habilitat i tècnica, que demostrin competència per aclarir la incògnita de qualsevol problema educatiu que se'ls plantegi i que respectin les regles ètiques de la professió?

Alguna cosa ens diu que no, sent aquesta cosa la pròpia experiència. Per les nostres vides han passat professors que complien amb el que es ve comentant, persones altament qualificades i que seguien al peu de la lletra l'ètica professional. En alguns casos, potser ens hauria agradat, per exemple, que haguessin explicat millor les lliçons, en altres, potser hauríem preferit veure més determinació en el compliment d'alguns compromisos ètics. Tot és millorable en aquesta vida, sí, però al cap i a la fi van acomplir amb el seu paper, van fer de mestres. I no obstant això, hem tingut altres que no han passat per les nostres vides, sinó que s'hi han quedat, que habiten en aquell lloc íntim i personal on guardem als nostres bons professors. Allà estan Don Manuel, la mestra Clara, el Joan o la senyoreta Isabel, cada un de nosaltres 
tindrà la seva pròpia llista de noms i cognoms, fins i tot d'afectuosos malnoms i sobrenoms. Ells van fer coses impossibles d'esborrar de les nostres ments i suprimir de les nostres ànimes. I bé sabem que no estem parlant de fets màgics o espectacles sofisticats, sinó de gestos típicament humans, senzills i bonics, tremendament fructífers i impossibles d'oblidar.

Els alumnes de Sòcrates, per exemple, se sentirien conquerits per una cosa tan humana, espontània i fecunda com pot ser la passió que un mestre posa en aprendre sense buscar res a canvi, sense esperar res més que aprofundir en el coneixement de les coses i gaudir amb això. S'explica que mentre li preparaven el verí amb el qual hauria de morir, es trobava el filòsof grec assajant amb una flauta, i quan li van preguntar el perquè de tan estrany comportament, va respondre que volia saber tocar aquesta melodia abans de morir (Ordine, 2013). Fets similars podrien trobarse en les vides i obres d'altres grans mestres de la humanitat, però no cal fixar-se només en els membres d'aquest selecte club, també podem mirar dins dels nostres centres educatius. Un recordarà les converses personals que va mantenir amb Don Manuel, i que tant el van ajudar per prendre sàvies decisions; I'altre evocarà la paciència amb la qual la mestra Clara acollia les seves entremaliadures i criaturades, i la finor amb la qual va aconseguir redreçar un comportament que no era gens saludable; aquell de més enllà rememorarà el sentit de l'humor amb el qual el professor Joan relativitzava problemes que a primera vista semblaven infranquejables, i amb el qual va aprendre que un altre món és possible; i aquest d'aquí creu, gràcies a la professora Isabel, que llegir és tan necessari com menjar, que les hores d'avorriment es poden transformar en delicioses hores de lectura.

Aquests professors, que tant recordem i tan bé ens van fer, ens ajuden a albirar l'envergadura i transcendència de la tasca educativa. Ells ens assenyalen que un professor pot ser alguna cosa més que un professional competent $i$ un defensor de la deontologia, que pot aconseguir resultats que van més enllà de l'aprenentatge del temari de torn i de l'establiment d'un clima escolar mínimament respectuós i simpàtic. Aquests professors ens inciten a pensar que l'educació, seguint l'eminent filòsof alemany Max Scheler, és sinònim d'humanització (Scheler, 1973). Ens suggereixen que educar té a veure amb mostrar un especial interès per l'alumne, això és, ajudar-lo, guiar-lo, acompanyar-lo, o com se li vulgui dir; ens assenyalen que estem davant d'una meravellosa aventura humanizadora, un extraordinari procés que ens fa homes i dones, un autèntic esdeveniment ètic ple de gestos i paraules que faciliten la transformació de tots els que allí es reuneixen, per descomptat també del professor.

El treball que aquí es presenta transcorre sobre aquest assumpte ara assenyalat. El principal objectiu és reflexionar sobre aquesta influència educativa i personal que un professor pot causar en els seus alumnes, i que produeix meravellosos i admirables resultats. Ben mirat, amb quelcom així és amb el que somien la gran majoria d'estudiants de les nostres facultats d'Educació quan manifesten que volen canviar vides, ser algú especial per als seus futurs alumnes, millorar el món o coses similars. També és una cosa semblant el que tracten d'aconseguir diàriament, amb molt d'esforç i davant un bon nombre d'obstacles no pocs dels professors que ja exerceixen com a tals. 


\section{Cercant l'artesà}

D'ara en endavant ens proposem elevar algunes propostes per a la formació de mestres, i en conseqüència i, principalment, per a les facultats d'Educació. Per descomptat, no ens considerem amb l'autoritat necessària com per dir què directrius s'han de seguir si es vol disposar d'aquests professors que anomenem insubstituïbles. I dit sigui de passada, resulta fascinant la valentia que demostren alguns en llistar concrets preceptes que cal complir per disposar dels millors professors possibles, com si això de formar un bon professor consisteix en encaixar peces d'un puzle, superar les proves d'una gimcana o reunir peces de diferents colors fins a guanyar la partida del Trivial. Més que donant lliçons sobre un tema tan complicat, ens sentim més còmodes convidant, suggerint coses que potser podrien orientar el quefer de les nostres facultats que es dediquen a formar mestres. Diem això perquè entenem que hi haurà centres universitaris que ja caminen fent coses semblants a les que aquí es puguin assenyalar. A més, es vol insinuar tot amb una prudència considerable perquè cada realitat universitària pugui fer una lectura particular, exclusiva i contextualitzada del que aquí es pugui dir.

Una facultat d'Educació té la missió de capacitar persones que volen educar petits i joves, com una facultat de Medicina té la comesa de formar individus que volen dedicar-se a curar persones o una de facultat de Dret té la tasca de preparar als que volen impartir justícia en múltiples àmbits. Raons com aquestes van ser el motor d'aquelles emblemàtiques i primigènies universitats medievals que es van conformar en facultats, i pel que es veu, són motius que encara es mantenen en peu, que han resistit vents i marees al llarg de la història. Quan una facultat d'Educació presenta a la comunitat una nova fornada de nous professors és com si aquesta corporació universitària tingués veu i digués: «Aquí tenen vostès a un nou grup d'homes i dones preparats per educar!, podem garantir que tenen les facultats necessàries per a això!, sí, els hem facultat per tal cosa!». Una graduació és una cosa tan seriosa com emocionant, és el resultat per excel-lència de la meravellosa idea de la universitat.

Durant els últims anys, així ho veiem nosaltres, sembla ser que aquest esperançador missatge s'ha vist acotat a l'àmbit de la competència, la tècnica, el procediment, l'habilitat, en fi, a tot allò que es reuneix al voltant del com es fa l'educació. Els successius grups d'homes i dones preparats per educar són coneixedors d'una infinitat d'aspectes relacionats amb el com, acumulen un elevat nombre de coneixements, saben com fer-se amb infinitat de recursos, en definitiva, sabran sortir més o menys airosos de qualsevol situació educativa que se'ls pugui presentar. Tot està molt bé i per descomptat seria molt pitjor el contrari. Gràcies a aquesta preparació podem parlar de professionals de l'educació, experts en l'àmbit educatiu, entesos en la qüestió d'ensenyar, competents en què altres aprenguin o coses per l'estil. Als que s'han graduat fa poc encara els falta l'experiència, fet que ocasiona que es puguin sentir orfes de tot les primeres vegades que es troben enmig d'alumnes, col.legues i famílies, és clar que sí, però la facultat per a ser professor ja està, queda acreditada en el títol acadèmic que està penjat en una paret de casa.

No obstant això, educar no és tan sols una professió, també pot ser concebuda com un art, tal com es va apuntar en el primer bloc d'aquest treball. És més, el professor que es dedica només a exercir la seva professió es deixa pel camí a l'artista 
que està cridat a ser. I tot bon artesà, assenyala Richard Sennet en un llibre meravellós, «manté un diàleg entre unes pràctiques concretes i el pensament; aquest diàleg evoluciona fins a esdevenir hàbits, els que estableixen al seu torn un ritme entre la solució i el descobriment de problemes» (Sennet, 2009, p. 21). Per l'artesà és fonamental la reflexió, l'esperit contemplatiu, l'especulació, filosofar o com se li vulgui dir; aquesta acció típicament humana és la que ajuda a considerar la realitat, a veurela com la transcripció i compendi de l'invisible o teòric. Ningú nega que es pugui ser un professor eficaç sense acudir al pensament o la cavil.lació, però alguna cosa ens diu que les altes cotes d'excel-lència s'assoleixen quan s'assumeix que per ser competent cal ser filòsof o alguna cosa semblant. I no menys important, alguna cosa ens diu també que el professor que en el seu quefer no incorpori una dimensió filosòfica va abocat a la rutina professional i personal, sí, el caràcter d'un professor pot ser rutinari.

No és de rebut donar classes un any i estar tots els següents repetint el mateix, fins i tot amb els mateixos exemples i acudits, com tampoc és lògic que un professor sigui la mateixa persona dia rere dia quan bé se sap que educar és canvi continu. Val la pena dir, que això de filosofar sense parar no és exclusiu del professor, incumbeix a qualsevol professional tal com explicava fa uns anys Donald Shön en un influent escrit (Shön, 1998), o pensaven molt abans que ell Arquímedes de Siracusa sobre els matemàtics o Galè de Pèrgam sobre els metges. L'estudiant entra en una facultat d'Educació per lloables motius. No volem ni pensar que hi hagi qui es matriculi per això de no tenir res millor a fer, ja que qui es forma com a professor per matar el temps té molts números de fer-lo perdre als altres. Dèiem que l'estudiant que accedeix a una facultat d'Educació s'hauria de veure embolicat des del primer minut en una superba missió, sentir com se li comença a regirar un cuc que mai més tornarà a estar quiet, en definitiva, hauria d'assumir on s'ha ficat realment. Aquesta estimulació, si es pot dir així, està en mans de la facultat, i sembla ser tan important que fins i tot podria cridar l'atenció d'ànimes despistades o desmotivades que ja d'entrada no esperen massa dels anys universitaris que l'esperen. Aquesta activació pot anomenar-se com la convocatòria a ser artesans de l'educació, una crida a filosofar indefinidament sobre el sentit d'actuació, la recerca de les millors decisions, és a dir, una citació per instal-lar-se per sempre més en l'ètica del professor. És bo allò que usualment es ve fent a les nostres facultats d'Educació, és a dir, que s'aprofiti el primer contacte amb l'estudiant per informar sobre qüestions com el pla d'estudis pel qual li tocarà transitar, les característiques del lloc en el qual es troba i potser una mica de la seva història, les persones a les quals pot acudir segons siguin els temes a tractar, els recursos de què pot disposar, els processos als quals s'ha d'ajustar, les associacions a les quals es pot inscriure, en definitiva, és important situar-lo de la millor manera possible sabent que tot i així sempre queden caps per lligar o coses per esbrinar. I no obstant això, no és suficient per revelar el que abans es comentava, per obrir-li la gana, per insuflar-les ganes de buscar l'artesà que està cridat a ser.

Aquesta anunciació pot adquirir diverses formes, i ben pensat no cal massa sofisticació. Potser seria suficient explicar-los als nous estudiants la història d'Albert Camus i el seu professor Germain, aquesta o altres que parlin de l'important que pot arribar a ser un mestre per a un alumne. També n'hi hauria prou amb gaudir d'una xerrada que donen aquests professors universitaris que aconsegueixen posar 
dempeus a l'auditori, que es commouen i emocionen quan parlen de què significa dedicar-se a l'educació, que inciten a sortir d'allà corrent per educar el primer que passi. I no estaria malament conversar amb mestres en exercici que puguin explicar als estudiants universitaris què estan esperant els nens i joves d'avui, les seves mirades i gestos els delaten, aquests alumnes esperen algú que els vulgui, algú de qui poder enamorar-se. Aquest tipus de manifestacions que poden impulsar l'estudiant a cercar l'artesà que porta dins és una mena de preludi per a altres coses. Ens referim a maneres de funcionar o condicions que ajudin a encarar aquesta recerca amb un mínim de garanties. Totes elles es reuneixen en un mateix missatge: un artesà es forma en un taller d'artesania i no en qualsevol altre lloc. A continuació presentem quatre circumstàncies que ens semblen importants per això, perquè una facultat d'Educació s'assembli a una cosa així, a una mena de taller de mestres i aprenents de l'educació.

\section{Ni un per a tots ni tots per a un, tots per a l'educació}

A les facultats d'Educació sol donar-se el següent esquema: es presenta un grup d'assignatures que estan orquestrades per diferents professors i que se succeeixen una rere l'altra. Cadascuna de les matèries que conformen aquesta antologia sol incloure els seus propis continguts, objectius d'ensenyament i d'aprenentatge, maneres d'avaluació, metodologia docent, competències a adquirir, bibliografia obligatòria i recomanada, i alguna que una altra cosa més que la burocràcia universitària exigeix omplir. Unes d'aquestes assignatures tenen Iloc a l'aula i altres en centres educatius configurant així a les conegudes pràctiques, fins i tot poden donar-se algunes que prenguin la forma d'una mena de servei a la comunitat educativa. Anar superant assignatures és anar acumulant crèdits per obtenir el títol desitjat, dit sigui de pas, una manera de procedir que recorda molt a la comercial.

Tot això, i alguna cosa més que ens haurem deixat en el tinter, es podria veure representat en una consigna que té una llarga història al darrere. Alguns ho coneixeran per tractar-se del lema, encara que no oficial, de Suïssa; i a la majoria potser ens sona més per ser el crit de guerra de D'Artagnan i els seus inseparables Athos, Portos i Aramis, els mosqueters més famosos del món que ens va presentar Alexandre Dumas. «Unus pro omnibus, omnes pro uno», un per tots i tots per un. Doncs bé, quan s'observa el funcionar d'una facultat d'Educació sembla que encaixa això d'un estudiant per a tots els professors i tots els professors per a l'estudiant. Fins i tot se li podria donar la volta i també es correspondria amb el que passa: un professor per a tots els estudiants i tots els estudiants per al professor. No hi hauria problema si tot estigués articulat per alguna trama, si hi hagués alguna narració que enllacés el que va passant; si, en definitiva, la formació de mestres tingués a veure amb la sensació d'una successió que té un cert sentit d'unitat. No obstant això, sol passar alguna cosa diferent, que aquesta formació s'assembla més a una successió de sensacions independents les unes de les altres. Tot i que no és ara el moment d'inquirir en què ocorre tal situació, hi ha motius evidents que la fomenten i que no passen desapercebuts. Ens referim, per exemple, al que sol passar en grans facultats, al fet que hi hagi professors que eduquen al mateix grup d'estudiants i paradoxalment no s'han assegut mai a parlar sobre ells. 
En aquest punt val la pena rescatar algunes de les idees de Wilhelm von Humboldt, considerat el pare de la universitat moderna, el model universitari que va néixer a començament del segle XIX i que tants èxits ha collit. Per a l'eminent pensador alemany: "Només la ciència que brolla de l'interior i pot arrelar en ell, transforma també el caràcter» (Abellán, 2008, p. 284). L'artesà de l'educació, aquell que manté un diàleg permanent entre el que fa i el pensament, necessita potser veure's embolicat en una circumstància diferent a l'anteriorment comentada, en una en què la ciència educativa germini dins d'ell. Aquesta idea, es miri per on es miri, demanda cooperació en el sentit més profund del terme, és a dir, sol-licita que s'obri al costat d'altres per assolir metes comunes. I és en aquest treballar colze amb colze on la condició humana del mestre treu el cap, és un cop de mà per edificar l'esdeveniment ètic que hauria de viure l'artista de l'educació. El mateix Humboldt ve a afirmar que: «Allò humà no pot desenvolupar-se més que en forma de cooperació» (Abellán, 2008, p. 286). A una facultat d'Educació, segurament també en qualsevol altra, el professor no està per a l'estudiant ni aquest últim està per al primer, tots dos són allà per l'educació, per buscar-se i trobar-se com artesans de tal àmbit. Sens dubte, són moltes les formes de concretar aquestes idees, gent amb el cap ordenat i una bona dosi de creativitat podria sorprendre'ns amb precises, agudes i concretes propostes. Aquí ens limitem a suggerir. El coneixement educatiu, com qualsevol altre, està conformat pel que es podria anomenar tòpics, per tot un seguit d'assumptes que conformen la trama de tal àmbit. Són temes que admeten diverses interpretacions, sí, que no estan tancats sinó en contínua construcció, també, però en tant que assumptes, són veritats de majoritària i consensuada acceptació. Que l'estudiant es faci amb ells és molt important per una senzilla raó: per protegir-se de la «opinologia», una mena de virus que avui dia campa al seu aire pels carrers i places i també ataca l'àmbit educatiu. Se'ns acut, potser és desgavellat veient com estan organitzades les nostres facultats, que aquests temes fossin treballats per equips de professors universitaris organitzats d'una manera particular.

Uns professors, els més preparats, podrien dedicar-se a explicar els tòpics com ells saben fer-ho, és a dir, d'una manera magistral. És més, fins i tot se'ls podria reservar una aula especialment preparada i decorada per a aquestes ocasions, un lloc de trobada màgica per a tots els estudiants i professors, sí, és important que aquests últims també hi siguin allà escoltant, pensant i intervenint. Poques coses hi ha més educatives per a un estudiant que observar als seus professors interpel-lantse i interrogant-se. Aquests espectacles docents ocuparien poques hores, les menys. La resta podria ser conduïda pels altres professors de l'equip, cada un d'ells fent-se càrrec d'un petit grup d'estudiants. Aquestes classes amb menys persones podrien convertir-se en autèntics laboratoris de recerca educativa. Professors i estudiants, encesos per les idees presentades i debatudes en les classes magistrals, han de tenir l'oportunitat de provar, assajar, experimentar, en fi, posar-se en perill davant allò que s'ha dit, atrevir-se a discernir si és així o no, si cal veure-ho d'una manera o d'aquella altra. I no es tracta d'atrevir-se a treballar per qualsevol cosa, sinó per acabar amb algunes idees clares, per fer-se amb alguna cosa sobre el que pensar, és a dir, per sortir del laboratori amb una mica d'ordre al cap, encara que això estigui cridat a desordenar-se a la següent classe. És gairebé un enigma que la investigació educativa que es porta a terme a les nostres facultats d'Educació sigui desconeguda pels estudiants, que allò que succeeix en els despatxos i sales de reunions, a pocs 
metres de les aules, quedi allà tancat amb pany i clau. El pensament emergeix quan es contrasta amb la realitat, i això ens hauria de suggerir que l'artesà en formació ha d'aprendre a investigar amb tot el que això implica.

\section{De l'estret camí al camp obert}

«No hi ha remei: per caminar amb encert a la selva de la vida cal ser culte, cal conèixer la seva topografia, les seves rutes o mètodes, és a dir, s'ha de tenir una idea de l'espai i del temps que es viu, una cultura actual» (Ortega i Gasset, 2005, p. 450). Aquestes paraules de Don José Ortega i Gasset dirigides a la formació universitària no haurien de caure en sac foradat. L'universitari, deia fa anys el grandíssim filòsof madrileny, és «el nou bàrbar», una persona que és tremendament especialista en alguna cosa i abusivament inculte en gairebé tota la resta. Què diria Don José avui? Respondre a aquesta pregunta requeriria un llibre a part. La llebre del dèficit de la formació cultural a la universitat la van aixecar ja fa anys Edward Hirsch a través d'un famós article i Allan Bloom mitjançant un famós llibre (Hirsch, 1983; Bloom, 1987). I pel que es veu, encara no hem pogut atrapar-la, si és que no l'hem perdut de vista definitivament, tal com assenyalen alguns autors de referència internacional (Llovet, 2011; Collini, 2012; Delbanco, 2012). El nivell d'especialització de la nostra formació universitària ha arribat a tal punt que, des del moment en què un estudiant comença uns estudis, siguin aquests quins siguin, comença a transitar una espècie de camí estret amb uns murs prou alts com per no veure més enllà.

La formació del futur artesà de l'educació hauria de ser interpel·lada per aquesta idea ja que li interessa i molt. Si hi ha un professional que ha de deixar de transitar un camí tremendament especialitzat en alguna cosa per caminar en camp obert, aquest és el mestre. Sospitem una cosa: a dia d'avui és possible que hi hagi graduats de mestres que no hagin tingut l'oportunitat de sortir de la sendera educativa. Dit d'una altra manera, pressentim que hi haurà estudiants a les acaballes de la carrera i no han estat convidats a relacionar-se amb les idees vives d'altres àrees de coneixement, nocions que són necessàries per interpretar l'existència humana i imprescindibles per convertir la professió en art, per transformar un simple procés de transmissió en una aventura humanitzadora. Per descomptat que es pot suposar que un estudiant de mestre, com qualsevol fill de veí, pot buscar-se les garrofes pel seu compte i mostrar-se com un exemplar autodidacta cultural, però aquest suposar no treu que la universitat hagi de renunciar a una de les seves ancestrals i principals missions.

Podríem trobar a qui defensi que per solucionar el problema cal tornar a les arts liberals, al trívium i al quadrívium, o almenys plantejar una cosa molt semblant. No creiem que sigui per tant, no cal retrocedir tant en el temps, encara que dit sigui de passada, alguna cosa han de tenir aquestes arts tan antigues i passades de moda quan d'alguna manera es mantenen en part del sistema universitari nord-americà. Seria suficient amb recuperar el sentit d'aquell emblemàtic programa d'estudis medieval hereu de l'organització platònica del coneixement; n'hi hauria prou amb plantejar una cosa semblant al que Don José va anomenar «Facultat de Cultura» (Ortega i Gasset, 1930), viver d'idees que provoquen l'alliberament de la foscor que produeix la ignorància. Se'ns ocorre alguna cosa. El primer any de carrera potser no hauria de 
ser de concentració en la ciència educativa, sinó de dispersió en totes les àrees possibles, una diàspora de coneixements i sabers que, per descomptat, mai deixi d'estar connectada amb el terreny educatiu. Dit d'una altra manera, abans d'encarar el camí de la formació en el magisteri dels estudiants haurien de poder caminar per altres terrenys com les matemàtiques, la història, la literatura, la música, la sociologia, la psicologia i la filosofia, llocs que, directament o indirectament, parlen de l'educació. En aquests terrenys que representen un camp obert es troben les idees que són necessàries per a poder veure, palpar, assaborir, sentir i viure l'educació com un art, com un esdeveniment ètic. Es podria plantejar que una facultat d'Educació organitzés els cursos, seminaris o assignatures que considerés necessaris per assolir la comesa presentat; o bé que entre diverses facultats, d'una mateixa institució universitària o de diverses, organitzessin un programa conjunt. Potser aquesta darrera opció ens sembla més encertada per una raó de pes que avui dia tendeix a passar desapercebuda en la formació de mestres. És important que hi hagi espais i moments en què els estudiants d'una facultat d'Educació convisquin amb estudiants i professors de diferents facultats que respiren aires diferents o que coneguin altres maneres de procedir. Això és una cosa que ajuda a assumir que hi ha altres realitats, altres maneres de concebre el món, i a fi de comptes, això és una cosa que viuran quan es dediquin a educar, quan tinguin al davant un grup de joves o infants observant amb els ulls ben oberts i escoltant atentament.

\section{Deixar de ser desconeguts i conversar, conversar i conversar}

La influència personal i educativa no és només una importantíssim comesa de l'educació preuniversitària, també és una part solemne de l'acadèmia. A la universitat l'estudiant segueix sent un subjecte d'aprenentatge moral i el professor també pot arribar a ser considerat com insubstituïble. És més, l'edat juvenil que és la que ve a coincidir amb la universitària sol ser l'etapa en què gradualment es forma un pla de vida. Però aquest procés de planificació vital cal entendre'l en tota la seva complexitat, i per a això gens millor que recórrer a les paraules d'Eduard Spranger: "Seria comprendre equivocadament aquest procés el pretendre reduir-lo a l'elecció d'una professió. No es tracta al principi ni tan sols de plans que neixin d'un cap plenament i clarament proposat, sinó que ens referim a la direcció que pren la vida interior, formant-se, amb la tendència d'impulsos i la pressió del món exterior, un paral-lelogram de forces. Així es forma l'ésser humà en les profunditats, en el laberint inconscient o inadvertit del seu interior» (Spranger, 1973, p. 66). La influència educativa i personal que el professor d'universitat pot exercir en els seus estudiants esdevé en diversos moments i espais que conformen l'actual educació universitària, en classes, seminaris, pràctiques de laboratori, fòrums virtuals o per què no dir-ho, en una simple conversa de passadís. No obstant això, hi ha un moment i un espai que sembla ser el més rellevant de tots: la tutoria personal. Hi centrava la seva mirada d'una manera especial l'influent cardenal John Henry Newman, i segurament per això ha resultat ser una ensenya de l'emblemàtic model universitari anglès (Newman, 1927).

Cal preguntar-se en quin estat ens trobem en relació amb aquest assumpte en les facultats d'Educació. Nosaltres tenim un possible diagnòstic: en no poques ocasions la tutoria personal adopta la forma de trobada informativa, en moltes altres la d'una una simple visita per resoldre problemes o conflictes burocràtics, sí, en alguna cosa similar a una finestreta de reclamacions, en alguna cosa que s'assembla a una 
taula d'atenció al client, si es prefereix així. Del que es tracta és que l'estudiant pugui estar informat de tot el que necessiti, i que disposi d'un recurs per poder solucionar les contrarietats que puguin aparèixer durant el seu periple acadèmic. En aquesta situació, resulta lògic, la tutoria no necessita una regularitat, obligatorietat, compromís d'assistència, ni res semblant a aquestes coses.

No tots els estudiants necessiten estar informats sempre, tampoc són tots els que sol-liciten hores de tutoria als seus professors, ni tan sols són tots els que tenen contratemps, o sí que els tenen però els solucionen pel seu compte i risc a través d'Internet. En definitiva, l'actual estat de la tutoria personal en les facultats d'Educació, això ens sembla almenys a nosaltres, és bàsicament una reducció o minimització del que podria ser, trobades anecdòtiques de perfectes desconeguts que en veritat estan cridats a mantenir una conversa sense fi. La tutoria universitària no és qualsevol cosa per al futur artista de l'educació. No és això una simple xerrada distesa i amable, sinó un diàleg en què sorgeixen i es plantegen temes importants i essencials, assumptes que toquen os, que tenen aspectes d'incidir en el caràcter i la personalitat moral de l'estudiant. I és que la universitat, per molt que avui ja no ho sembli, no és només una institució epistemològica dedicada al coneixement, també és una institució ontològica, és a dir, centrada en l'ésser.

A la tutoria universitària no hi ha un director d'orquestra, no hi ha un patró de vaixell que marca un rumb determinat. La tutoria és massa imprevisible com per encotillar en competències o continguts, és massa capritxosa com perquè es deixi calibrar per indicadors, rúbriques o resultats. La tutoria universitària no té conclusió, sempre està oberta, sempre deixa alguna cosa per al següent partit. El seu valor, per tant, no està en el que es conclou, sinó en les paraules que la conversa va dipositant en les ments i ànimes dels que hi participen. A la tutoria, així concebuda, treuen el cap dues interessants qüestions. La primera: que el futur artista de l'educació està cridat a conrear la seva pròpia autodeterminació, a plantar aquelles llavors que, a la seva manera, li podran potser convertir en un d'aquests professors insubstituïbles. Dit d'una altra manera, la tutoria universitària representa una esplèndida ocasió perquè l'estudiant d'educació vagi descobrint per ell mateix el que està cridat a ser, cosa que no està determinat ni tancat. I és que, tal com afirma el filòsof Daniel Innerarity, «una autodeterminació assolida seria, per tant, la de qui tracta de realitzar un projecte de vida prometedor i no es deixa encadenar per aquest projecte» (Innerarity, 2001, p. 40).

I la segona: a la tutoria s'aprèn a assumir que un va a formar part de l'elit de la seva comunitat, en aquest cas, de l'elit del cos de mestres. Cal entendre bé això últim per no caure en prejudicis o errades interpretacions. Etimològicament parlant, l'elit no és aquell grup d'individus que es desvincula de la comunitat, o que disposa d'alguna cosa oposat al comú, sinó que és aquell grup de persones que s'involucra en el propi, i sobretot l'aliè, amb tot el seu ésser, amb elevat sentit de la responsabilitat. Els mestres, bé ho sabem, no són una classe social privilegiada i envejada, però sí que tenen una mica de dirigents en tant que destaquen pels seus gustos, formes de vida, gestos, pensaments, valors, etc. I certament, disposar d'aquestes persones, fins i tot es podria dir exemples errants, és una necessitat de qualsevol sistema educatiu. Vist així, tal com assenyala Steiner (2004), i almenys en la nostra realitat, estem man- 
cats d'universitaris, i per tant també de futurs mestres, d'elit, de persones que s'enfrontin a l'actual situació social, una espècie de projecte que tendeix a amagar la responsabilitat social i comunitària sota la bandera de l'autonomia personal i la llibertat. La tutoria tal com nosaltres l'entenem no és una tasca fàcil. D'una banda, exigeix que hi hagi professors universitaris que defensin això que la conversa personal amb els seus estudiants, futurs mestres ni més ni menys, és una part fonamental del seu quefer. Certament, sempre quedarà el dubte de si qualsevol professor universitari disposa de les condicions personals necessàries per emprendre tan important tasca. D'altra banda, requereix que les facultats d'Educació situïn a la tutoria en un lloc de preferència, que la incloguin d'una manera o d'una altra en els seus plans d'estudis, que no la tractin com una qüestió que depengui de l'elecció personal de cada estudiant i professor.

\section{Viure quelcom semblant al quixot}

Aquest últim suggeriment podria estar dirigit a qualsevol facultat, i per tant, també a les d'Educació. Ens sorprèn escoltar un missatge que sobrevola en els centres educatius quan contracten als acabats de graduar. D'una manera o d'una altra, i cada vegada més, s'escolta que són ells els que s'han de fer càrrec d'ensenyar als nous mestres a treballar en equip, que han de transmetre'ls determinats hàbits morals, fomentar en ells la responsabilitat o qüestions per l'estil. No es tracta de renegar dels èxits assolits per la formació universitària durant els últims anys que sens dubte han estat considerables, del que es tracta és de mantenir en peu la formació moral, part essencial de la missió de la universitat; o si es prefereix, que no atenguem aquesta formació humana com cal i anem parlant de formació universitària quan en veritat estem parlant d'una altra cosa. I no diem això perquè la formació que esdevé en la universitat hagi d'estar més adaptada a la realitat, sinó per tot el contrari, perquè sigui alguna cosa així com un interval, una pausa en el temps. Sí, defensem una formació que realment sigui un intermedi entre, d'una banda, l'educació i les formes de vida que l'han precedit i que per múltiples raons són diferents a ella i, d'altra banda, una cosa que està per arribar, una futura professió i esdevenir vital que es poden imaginar, però que no es coneixen de manera exacta.

No es tracta d'un interval qualsevol, d'un període de temps per agafar aire i refrescar-se, ni de l'abandó o aparcament d'altres activitats. Del que es tracta més aviat és de poder dedicar-se sense lligams a una activitat única i excepcional: la de tractar de comprendre el món des d'una determinada perspectiva examinant-se a un mateix en l'esmentat exercici de comprensió. Tal activitat, típicament i profundament humana, no depèn de cap dret prèviament adquirit, com pot ser el dret a ser universitari, ni de cap prerrogativa posterior, com la de garantir que un va a poder guanyar-se la vida de la millor manera possible. L'autèntic privilegi que atorga i garanteix la universitat és la de ser estudiant. Això exigeix repensar algunes qüestions. Una d'elles és presentar de manera explícita i solemne la vida universitària, l'interval de temps en què un ha decidit participar-hi. No seria una pèrdua de temps que els estudiants, i també els professors, coneguessin, per exemple i sense anar més lluny, quin és el significat de la paraula o la frase que acompanya l'escut de la seva universitat que tantes vegades veuen impresa en documents, que engalana les aules i passadissos, o que porten inscrita en les seves carpetes i agendes. 
Una altra qüestió interessant és el plantejament de la vida universitària. Per això és necessari recuperar el sentit de totes aquelles activitats que complementen a les merament acadèmiques i que les enriqueixen. Ens referim a activitats que no són merament folklòriques, sinó que tenen ingredients formatius com la pràctica de l'esport, la música o el teatre, la participació en actes culturals, la pertinença a associacions estudiantils, el voluntariat universitari, etc. Al manteniment d'aquestes activitats s'han dedicat especialment les universitats nord-americanes, i encara que pugui tenir alguna cosa a veure amb el màrqueting o l'atracció de suculents ingressos, el seu manteniment sol estar fonamentat en l'educació integral i humanística dels estudiants (Colby, Ehrlich, Beaumont i Stephens, 2003). La darrera qüestió, i segurament la més important, és el manteniment i la defensa dels hàbits morals, d'aquestes maneres d'estar en la vida universitària, i en tantes altres que puguem imaginar. No es tracta tan sols de tallar certes pràctiques o de fomentar determinats costums perquè sí, o només perquè, suposadament, unes entorpeixen i altres afavoreixen el creixement humà, del que es tracta és d'apostar per uns hàbits i renunciar a altres perquè faciliten i entorpeixen respectivament la vida bona universitària. Així, per exemple, subratllar els llibres de la biblioteca, pràctica certament comuna a les nostres universitats, reflecteix descortesia o desconsideració cap al bé públic, i representa una vida universitària que pateix de sentit de pertinença a la comunitat de la universitat. El mateix podria dir-se de les parets pintades i les taules ratllades, de ser impuntual o aixecar-se en mig de classe, i tantes altres accions que potser són útils per a una bona vida, però per a res són adequades per a una vida bona.

Tot això no només va en perjudici de l'estudiant que així es comporta i actua, sinó que també va en contra de la pròpia universitat, de la seva missió educativa. La vida universitària que concebem i defensem inclou una repulsió d'allò baix i innoble, el desdeny, la vulgaritat, la mandra, el que és fàcil i còmode. Tot el que s'ha dit, així ho considerem, exigeix un treball en equip del professorat que conforma una facultat d'Educació, que tots es posin d'acord a l'hora de, per exemple, aplaudir determinats comportaments i censurar altres. Es podria confiar en el criteri personal de cada professor, en el que cada un a nivell personal considera amb relació a l'assumpte, això és una cosa que de fet es practica en la majoria de facultats d'Educació durant els últims anys, especialment en les institucions públiques i de grans dimensions. Però al nostre entendre aquesta manera de procedir sol acabar en el desmembrament de la vida universitària, sí, augmenta la manca de coherència i provoca que no hi hagi tantes vides universitàries com a professors amb els quals es creua cada estudiant. Una cosa ens diu que només qui viu quelcom semblant a allò que va viure el quixot, una mena de procés de transformació vital fecund $\mathrm{i}$ inexplicable està en disposició d'aconseguir el mateix amb altres, amb els infants i joves que esperen allà fora en els centres educatius. Una cosa ens diu que qui ha viscut una aventura humanitzadora amb un cert sentit pot atrevir-se a aventurar-se amb altres, alguna cosa ens diu que qui s'ha vist immers en un autèntic esdeveniment ètic durant la seva formació com a mestre, pot convertir en realitat una possible formació de mestres que aquí s'ha tractat d'explicar. 


\section{Referències}

Abellán, J. (2008) «La idea de universidad de Wilhelm von Humboldt». A Oncina, F. (Ed.), Filosofía para la universidad, filosofía contra la universidad (de Kant a Nietzsche). Madrid, Dykinson, 2008, pp. 273-296.

Bloom, A. (1987) The closing of American mind. New York, Simon and Schuster.

Colby, A.; Ehrlich, Th.; Beaumont, E. i Stephens, J. (2003) Educating citizens. San Francisco, Jossey-Bass.

Collini, S. (2012) What are Universities for? London, Penguin Group.

Delbanco, A. (2012) College, What it was, is, and should be. New Yersey, Princeton University Press.

Hirsch, E. (1983) «Cultural Literacy», The American Scholar, 52(2), p. 159-169.

Innerarity, D. (2001) Ética de la hospitalidad. Barcelona, Península.

Llovet, J. (2011) Adiós a la universidad. El eclipse de las humanidades. Barcelona, Galaxia Gutenberg.

Newman, J.H. (1927) The idea of a university. New York, Longmans Green and Co.

Ordine, N. (2013) La utilidad de lo inútil. Manifiesto. Barcelona, Acantilado.

Ortega y Gasset, J. (1930) La misión de la universidad. Madrid, Revista de Occidente.

Ortega y Gasset, J. (2005) «En el centenario de una universidad». A Obras Completas. Madrid, Alianza Editorial, tom V, p. 466-475.

Scheler, M. (1973) Sociología del saber. Buenos Aires, Siglo Veinte.

Sennet, R. (2009) El artesano. Barcelona, Anagrama.

Shön, D. (1998) El profesional reflexivo. Barcelona, Paidós.

Steiner, G. (2004) La idea d'Europa. Barcelona, Arcàdia.

Spranger, E. (1973) Psicología de la edad juvenil. Madrid, Revista de Occidente. 


\section{Invitaciones para la formación de maestros}

Resumen: Necesitamos buenos profesores, los mejores posibles. Profesionales de la educación que acumulen muchos conocimientos y los sepan explicar, que estén a la última en nuevas tecnologías y en novedosas corrientes psicopedagógicas, y también requerimos profesores que cumplan con la deontología de la profesión docente. Ahora bien, ¿son solo así los buenos profesores que necesitamos? Algo nos dice que no, siendo ese algo la propia experiencia. Hemos tenido profesores que no han pasado por nuestras vidas, sino que se han quedado en ellas. Ellos hicieron cosas imposibles de borrar de nuestras mentes y almas, ellos tuvieron gestos típicamente humanos, sencillos y hermosos. Estos profesores nos demuestran que la educación puede llegar a ser una maravillosa aventura humanizadora, un auténtico acontecimiento de transformación humana. Este trabajo presenta algunas invitaciones para la formación de este tipo de maestros.

Palabras clave: Formación de maestros, Ética, Formación del carácter, Educación Superior.

\section{Des invitations à la formation d'enseignants}

Résumé: Nous avons besoin de bons professeurs, les meilleurs qui soient ; des professionnels de l'éducation qui accumulent de nombreuses connaissances et qui sachent les expliquer, qui restent au fait des plus récentes technologies et des nouveaux courants psychopédagogiques. Et il nous faut aussi des professeurs qui respectent la déontologie de la profession d'enseignant. Cela dit, les bons professeurs que nous recherchons doivent-ils présenter uniquement ces caractéristiques? Quelque chose nous dit que non : notre propre expérience. Nous avons eu de bons professeurs qui n'ont pas traversé notre vie, mais qui y sont restés; qui ont fait des choses impossibles à effacer de notre esprit et de notre âme, qui ont fait preuve d'humanité à travers des gestes simples et admirables. Ces professeurs nous démontrent que l'éducation peut s'avérer une aventure humanisante merveilleuse, un véritable événement de transformation humaine. Ce travail présente quelques invitations à la formation de ce type d'enseignants.

Mots clés: Formation d'enseignants, éthique, formation du caractère, enseignement supérieur.

\section{Proposals for training teachers}

Abstract: We need good teachers, the best we can have: teachers who are knowledgeable and who can explain knowledge; teachers who can keep abreast of the new technologies and innovative trends in educational psychology and teaching, and who respect the ethical code of the teaching profession. But experience tells us that the good teachers we need do more than this. All of us remember at least one teacher who did not so much pass through our life, as stay in it. She or he made certain things impossible to erase from our minds and hearts through typically human, simple and beautiful gestures. These teachers showed us that education can be a wonderful, humanising adventure, a true event of human transformation. This paper makes proposals about how to help trainees teachers do this.

Keywords: Teacher education, ethics, character development, higher education. 